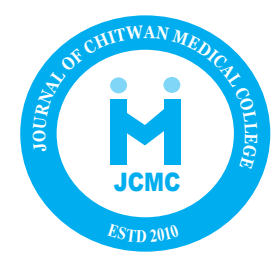

Journal of Chitwan Medical College 2018; 8(23): 1-4

Available online at: www.jcmc.cmc.edu.np

\title{
ORIRILL RESERRQLARTIGL
}

\section{ANALYSIS OF CERVICAL CANCER SCREENING AT PATAN HOSPITAL NEPAL}

\author{
Laxmi RC, ${ }^{1 *}$ Prashant Shrestha, ${ }^{1}$ Binita Pradhan ${ }^{1}$ \\ ${ }^{1}$ Department of Obstetrics and Gynecology, Patan Academy of Health Science, Lagankhel. \\ *Correspondence to: Dr. Prashant Shrestha, Patan Academy of Health Science, Lagankhel. \\ Email: pshrestha76@gmail.com
}

\begin{abstract}
Background: Cervical cancer is among the most common cancer in women of Nepal. This disease undergoes a state of prolong premalignant state during which it can be detected and treated effectively. Papanicolaou (pap) smear is an effective method of identifying premalignant disease and with this there has been more than 90 percent decrease in the incidence of cervical cancer. The objective of this study was to analyse the pattern of Pap smear screening at Patan hospital. Methods: This is a population based retrospective cross-sectional study conducted at Patan hospital, Lagankhel. The study population includes women with gynaecological symptoms who required Pap smear screening over a period of two years. The pap smear data were collected and statistical analysis was done. Results: Among 1993 smear studied, only 89 reports had some form of intraepithelial lesion. The most prevalent lesion was low grade intraepithelial lesion $(49.43 \%)$ whereas the least common was Atypical glandular cells $(1.12 \%)$. The highest number of respondent were in the age of $30-40$ years whereas the lowest was in the group of age less than $\mathbf{2 0}$ years. The patient who had abnormal epithelial lesions had multiple symptoms like vaginal discharge, vulval itching and lower abdominal pain. Conclusions: Pap smear screening should be started by the age of 21 and should be done in all women with any gynaecological symptoms.
\end{abstract}

Keywords: Cervical cancer, LSIL, Pap smear, Screening

\section{INTRODUCTION}

Cervical cancer is fourth common cancer affecting women and also fourth common cause of cancer death in women, worldwide. $70 \%$ of it occurs in developing countries. ${ }^{1}$ However, it is most common cancer among Nepalese women. ${ }^{2}$ According to the International Agency for Research on Cancer (IARC), the incidence of cervical cancer can be reduced by 90 percent through periodic screening. ${ }^{3}$

The Papanicolaou (Pap) smear identifies abnormal cells sampled from the transformation zone, where cervical dysplasia and cancer arise. As cervical cancer undergoes prolong state of dysplasia, pap smear helps to identify cancer at the earliest. According to Alliance for cervical cancer prevention, this test is very specific but moderately sensitive. ${ }^{4}$ For the uniformity on reporting, Bethesda System is universally used for reporting the results. 5
Knowing about the incidence of disease would help to emphasize the importance of periodic screening and target in need population which would make screening method more cost effective.

\section{METHODS}

This is a population based descriptive cross sectional study conducted in the department of Obstetrics and Gynecology at Patan Academy of Health Science, Lalitpur, Nepal. In this study, patients who visited Gynecology OPD from the period of 2069/9/17 to 2071/8/ 17 (January 1, 2013 - December 3 2014) were screened for cervical cancer through PAP smear. The reports were collected from the Pathology department and analyzed. The reports included patients age, presenting symptoms and diagnosis which was made in accordance to Bethesda system of reporting cervical smear. So these determinants were used for the statistical analysis. Results were recorded as per the Performa and analyzed by using standard statistical methods (Microsoft Excel 16.0). 
Approval from the institutional review board was taken for the study.

\section{RESULTS}

Total of 2084 slides were studied over the period of two years and one month. Among those, 91 slides were found to be inadequate for reporting. So total 1993 smear were studied. The age distribution among the respondent ranged from 19 years to 78 years with the mean of 36.41 . The highest number of respondent $41.49 \%$ were in the age of $30-40$ years whereas the lowest was in the group of less than 20 years $(0.05 \%)$. The mean age among the patient with epithelial abnormality was 39.12 years.

The reporting of pap smear was based on Bethesda system. Among 1993 pap smear report, only 89 reports $(4.45 \%)$ had some form of intraepithelial lesion. Among those 89 patients, most (49.43\%) had low grade intraepithelial lesion whereas only 1 (1.12\%) had Atypical glandular cells (AGUS).

Regarding the clinical presentation, the respondent who had positive pap smear report had symptoms like $p / v$ discharge, pain lower abdomen and genital itching. Majority of those patients had multiple symptoms and only $8 \%$ had routine screening without any genital symptoms.

\section{DISCUSSION}

The association of human papillomavirus (HPV) with cervical cancer is very well documented. The oncogenic strains of HPV when infect the cervical cells lead to metaplastic changes in it. So the pap smear is a microscopic examination of those cells scraped from the cervix to detect the cancerous changes. It has been shown worldwide that screening for precursors of cervical cancer by means of Papanicoloau (Pap) smears substantially reduces the incidence of invasive cancer.

This is a retrospective cross sectional study aimed at studying the pap smear pattern at Patan hospital. During 2 year of study period, total of 2084 smears were studied, among which 91 (4.36\%) were unsatisfactory. This is almost equal to studies done by Sarma et al.6 and Alta et al.7 in which unsatisfactory smears were $6.6 \%$ and $6.31 \%$ respectively. However, this number is much less than the study by Patel et al.8 which had $8.9 \%$. so the total 1993 pap smear reports were studied.

The prevalence of abnormal epithelial lesion in this study was found to be $4.45 \%$ and this is very much comparable to other countries like the United States and India where rates has ranged from 2.3 to $6.6 \%$ and $1.87 \%$ to $5.9 \%$ respectively.9 Current study determines 1903 cases $(95.53 \%)$ of negative for intraepithelial lesion or malignancy (NILM) with normal pap smears, non - specific inflammation and infections like bacterial vaginosis, trichomoniasis and fungal infections. This results corresponds to the study done by Ranabhat et al.10 where the incidence of NILM was found out to be $98.29 \%$.

Among those 89 patients with some form of intraepithelial lesion, the highest number was among the LSIL and ASCUS, $49.43 \%$ and $25.84 \%$ respectively. This is similar to many other studies where the highest number is being shared by these two diagnoses. These day women are aware that any abnormal gynecology symptoms should be evaluated. And with some form of symptoms, they undergo screening. So screening at the earliest could be a reason to find out such large number of LSIL and ASCUS as these are the most initial process during the metaplasia. However, more severe form of disease process like HSIL and AGUS, $14.6 \%$ and $1.1 \%$ respectively was also noted in this study.

Among the total study population, the mean age of patients was 36.41 whereas the mean age among the abnormal result was 39.12. Maximum numbers of cases 827 (41.49\%) were in the age group of 30 -40 years whereas the least was in the group of less than 20 years. This pattern of age distribution was similar to the study done by Patel et al. 8 which could probably be due to higher sexual activity among the married women. However, the cases ranged from 19 years to 78 years of age. And among those ladies who were more than 70 years had history of uterovaginal prolapse.

Many patients who underwent pap smear had multiple symptoms like vaginal discharge, genital itching, pain lower abdomen and uterovaginal prolapse. Among those with positive epithelial abnormality, $70 \%$ had vaginal discharge, $35 \%$ had genital itching and $40 \%$ had pain lower abdomen. However, $7 \%$ had no symptoms and had routine screening. This finding is similar to the study done by Sunita et al.11 


\section{CONCLUSIONS}

This study emphasized the importance of Pap smear screening for early detection of premalignant and malignant lesions of cervix. However, larger study populations and detection of common HPV strains are required to form a proper Pap smear screening program at national level. Based on our findings, we recommend Pap smear screening to be started by the age of 21 and should be done in all women with any gynecological symptoms.

Figure

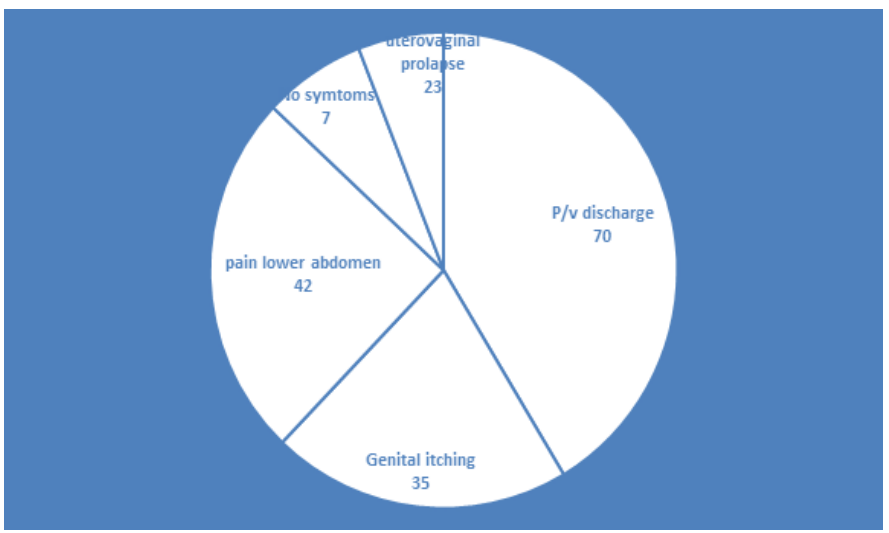

Figure 1. Distribution of symptoms among positive pap smear respondent

Table

\section{Table 1. Age distribution}

\begin{tabular}{|l|l|l|}
\hline Age & Total Number & Percentage \\
\hline$<20$ years & 1 & $0.05 \%$ \\
\hline $20-30$ years & 354 & $17.8 \%$ \\
\hline $30-40$ years & 827 & $41.49 \%$ \\
\hline $40-50$ years & 527 & $26.44 \%$ \\
\hline $50-60$ years & 235 & $11.78 \%$ \\
\hline $60-70$ years & 26 & $1.3 \%$ \\
\hline$>70$ years & 23 & $1.15 \%$ \\
\hline
\end{tabular}

Table 2. Distribution of abnormal smears

\begin{tabular}{|l|l|l|}
\hline Diagnosis & Total Number & Percentage \\
\hline $\begin{array}{l}\text { Low grade Squa- } \\
\text { mous intraepithe- } \\
\text { lial lesion (LSIL) }\end{array}$ & 44 & $49.43 \%$ \\
\hline $\begin{array}{l}\text { High grade Squa- } \\
\text { mous intraepithe- } \\
\text { lial lesion (HSIL) }\end{array}$ & 13 & $14.6 \%$ \\
\hline
\end{tabular}

\begin{tabular}{|l|l|l|}
\hline $\begin{array}{l}\text { Atypical squamous } \\
\text { cells of undeter- } \\
\text { mined significance } \\
\text { (ASCUS) }\end{array}$ & 23 & $25.84 \%$ \\
\hline $\begin{array}{l}\text { Atypical glandular } \\
\text { cells (AGUS) }\end{array}$ & 1 & $1.12 \%$ \\
\hline $\begin{array}{l}\text { Sqauamous Cell } \\
\text { Carcinoma (SCC) }\end{array}$ & 8 & $8.98 \%$ \\
\hline
\end{tabular}

\section{REFERENCES}

1. Ferlay J, Soerjomataram I, Ervik M, Dikshit R, Eser S, Mathers C et al. GLOBOCAN 2012 v1.0, Cancer Incidence and Mortality Worldwide: IARC Cancer Base No. 11. Lyon, France: International Agency for Research on Cancer; 2013.

2. Family Health Division (FHD). National Guideline for Cervical Cancer Screening and Prevention in Nepal; 2011.

3. Screening for squamous cervical cancer: duration of low risk after negative results of cervical cytology and its implication for screening policies. IARC Working Group on evaluation of cervical cancer screening programmes. Br Med J (Clin Res Ed) 1986; 293:659.

4. Alliance for cervical cancer prevention. Pap smear: An important but imperfect screening method. http://screening.iarc.fr/doc/RH_pap_ smears.pdf

5. Tailor HJ, Patel RD, Patel PR, Bhagat VM. Int J Res Med Sci. 2016 Jan;4(1):286-288.

6. Sarma U, Mahanta J, Talukdar K. Pattern of abnormal cervical cytology in women attending tertiary hospital. Int J Sci Res Pub 2012;2(12):14.

7. Atla BL, Prasad Uma, M. Shamili, S. Satish Kumar. Cytological patterns of cervical pap smears with histopathological correla-tion. Int J Res Med Sci. 2015;3(8):1911-1916.

8. Patel $C B$, Shah PC, Bhagat VM. A role of cervical Pap smear as a screening tool in diagnosis of lesions of cervix - a one-year study. International Journal of Medical Science and Public Health. 
2016 Sep 1;5(9):1841-5.

9. Mulay K, Swain M, Patra S, Gowrishankar S. A comparative study of cervical smears in an urban Hospital in India and a population-based screening program in Mauritius. Indian Journal of Pathology and Microbiology. 2009 Jan 1;52(1):34.

10. Ranabhat SK, Shrestha R, Tiwari M. Analysis of abnormal epithelial lesions in cervical Pap smears in Mid-Western Nepal. J Path Nep. 2011;1(1):303.

11. Bamanikar SA, Chandanwale SS, Baravkar DS, Dapkekar P. Study of Cervical Pap Smears in a Tertiary Hospital. Indian Medical Gazette. 2014: 250-4. 